Review Article

\title{
3D Printing Decellularized Extracellular Matrix to Design Biomimetic Scaffolds for Skeletal Muscle Tissue Engineering
}

\author{
Silvia Baiguera $\mathbb{D}^{1,2,3}$ Costantino Del Gaudio ${ }^{1},{ }^{4}$ Paolo Di Nardo, ${ }^{2,3,5}$ Vittorio Manzari, $^{2}$ \\ Felicia Carotenuto $\mathbb{D D}^{1,2,3}$ and Laura Teodori ${ }^{1,3}$ \\ ${ }^{1}$ Department of Fusion and Technologies for Nuclear Safety and Security, Diagnostic and Metrology (FSN-TECFIS-DIM), \\ ENEA, Italy \\ ${ }^{2}$ Department of Clinical Science and Translational Medicine, University of Rome "Tor Vergata", Italy \\ ${ }^{3}$ Interdepartmental Center for Regenerative Medicine (CIMER), University of Rome "Tor Vergata", Italy \\ ${ }^{4}$ E. Amaldi Foundation, Via del Politecnico snc, 00133 Rome, Italy \\ ${ }^{5}$ L.L. Levshin Institute of Cluster Oncology, I. M. Sechenov First Medical University, 119991 Moscow, Russia
}

Correspondence should be addressed to Silvia Baiguera; sbaiguer@libero.it and Felicia Carotenuto; carotenuto@med.uniroma2.it

Received 8 July 2020; Revised 8 September 2020; Accepted 27 October 2020; Published 17 November 2020

Academic Editor: Despina Deligianni

Copyright (C) 2020 Silvia Baiguera et al. This is an open access article distributed under the Creative Commons Attribution License, which permits unrestricted use, distribution, and reproduction in any medium, provided the original work is properly cited.

Functional engineered muscles are still a critical clinical issue to be addressed, although different strategies have been considered so far for the treatment of severe muscular injuries. Indeed, the regenerative capacity of skeletal muscle (SM) results inadequate for large-scale defects, and currently, SM reconstruction remains a complex and unsolved task. For this aim, tissue engineered muscles should provide a proper biomimetic extracellular matrix (ECM) alternative, characterized by an aligned/microtopographical structure and a myogenic microenvironment, in order to promote muscle regeneration. As a consequence, both materials and fabrication techniques play a key role to plan an effective therapeutic approach. Tissue-specific decellularized ECM (dECM) seems to be one of the most promising material to support muscle regeneration and repair. 3D printing technologies, on the other side, enable the fabrication of scaffolds with a fine and detailed microarchitecture and patient-specific implants with high structural complexity. To identify innovative biomimetic solutions to develop engineered muscular constructs for the treatment of SM loss, the more recent (last 5 years) reports focused on SM dECM-based scaffolds and $3 \mathrm{D}$ printing technologies for SM regeneration are herein reviewed. Possible design inputs for 3D printed SM dECM-based scaffolds for muscular regeneration are also suggested.

\section{Introduction}

The reconstruction of skeletal muscle (SM) due to volumetric muscle loss (VML) still remains a complex and unsolved task, and the development of ad hoc strategies to promote functional tissue regeneration, following muscular traumas or disease, is a real need $[1,2]$.

To develop muscle grafts that actually reconstruct and restore SM large-scale injuries, different tissue engineered strategies have been developed; however, a suitable biomimetic solution to obtain functional muscular constructs has not, till now, be found. Therefore, novel approaches that can facilitate safe bigger muscle tissue repair and regeneration should be developed [3].

The ideal biomaterial should fill the VML, including the muscular basal lamina, sustain cells/stem cells activity, and promote cellular orientation, alignment, and maturation, allowing access to vascular and neural cells $[4,5]$. For this aim, dealing with the tissue-specific extracellular matrix (ECM), properly treated, can represent a suitable option to define ad hoc therapeutic protocols. The ECM, indeed, contains numerous bioactive molecules, such as growth factors and cytokines, regulates cellular activities, and provides a physical ultrastructure that accommodates peculiar cell types 
[6-8]. Moreover, it has been demonstrated that ECM basal lamina plays an essential role in the regeneration process, acting as a tissue template and secreting chemotactic factors for stem cell recruitment [9-11]. For these reasons, ECMbased scaffolds, acting as regenerative templates and modulating the healing process, seem to be one of the most promising and interesting means to support muscle regeneration and repair [12]. Moreover, using ECM-derived scaffolds to generate new organs for transplantation has been suggested as a potential method to be effectively considered, and it has been included among the 10 most significant developments in the last 30 years [13].

In this regard, also the selection of the fabrication technique is pivotal to positively drive the cell response guided by the scaffold architecture. Additive manufacturing (AM) has recently emerged as a valuable methodology to produce geometrically defined three-dimensional structures, significantly improving their physiological relevance through the architectural mimicking of native tissues and organs. Particularly, 3D printing technology overcomes major drawbacks of conventional scaffolding techniques, including the limited control over the $3 \mathrm{D}$ structures of engineered tissues and the reduced reproducibility [14]. In this context, stereolithography, for instance, can usefully support the fabrication of biomimetic scaffolds for muscle repair, being characterized by the highest resolution level and being thus capable to fabricate aligned structural elements with the characteristic size of muscle fibers.

With the aim to identify innovative biomimetic solutions to develop engineered muscular constructs for the treatment of SM loss, the more recent (last 5 years) approaches including SM dECM-based scaffolds and 3D printing technologies for SM regeneration are herein investigated. Moreover, possible design inputs for 3D printed SM dECM-based scaffolds for muscular regeneration are also suggested. This review was therefore structured to briefly introduce the skeletal muscle tissue and its specific characteristics. Subsequently, in order to address VML issues, the potential role of the SM $\mathrm{dECM}$ as an instructive naturally derived material and the related $3 \mathrm{D}$ printing methodologies capable to process it for fabricating a biomimetic scaffold are discussed.

\section{Skeletal Muscle Tissue}

With more than 600 different muscles, SM constitutes about $40 \%$ of the human body mass, and it is the most common muscle tissue. It consists of long, parallel, multinucleated cells (muscle fibers) wrapped by a thin connective tissue (endomysium) and bounded together by collagenous sheets (perimysium), forming the fiber bundle. Several muscle bundles, enveloped together by a thick collagenous external sheath (epimysium), form a muscle. Muscle fibers may range from 10 to $100 \mu \mathrm{m}$ in diameter and from a few millimeters to many centimeters in length [15]. They are highly specialized to produce force and movement and are connected both to the vascular network, for constant nutrients and metabolite delivery and waste removal, and to the neuronal network for activation and contraction. Functionally, muscle fibers are often distinguished between slow and fast fibers depending on their metabolic activity (respectively, oxidative, or glycolytic metabolic pathways) and on the myosin heavy chain proteins within the contractile fiber apparatus [16]. SM fibers appear striated due to the alignment of repeated functional contractile units called sarcomeres, which consists of interposed filaments of actin and myosin [17].

SM tissue is characterized by a regenerative capacity, due to the activation of progenitor muscle cells (satellite cells), located underneath the basal lamina, which can fuse with healthy muscle fibers to regenerate and repair the damaged fibers. However, since SM fibers cannot divide, this repair property is limited only to small-scale injuries. When muscle mass loss is greater than $20 \%$, muscular regenerative capacity is inadequate and may lead to extensive and irreversible fibrosis, scarring, and loss of muscle function [18]. Traumas associated with VML result then related to lasting functional impairment and impacts patient's life quality by significantly reducing the movement ability. While mild/moderate traumas can be treated using different established approaches $[19,20]$, severe and extensive muscle injuries often require surgical management $[2,21]$. Although transposition flaps represent the current clinical gold standard for VML treatment [22], they are far from being ideal because of the risk for donor site morbidity, reduced muscular function, graft failure, and high costs [1, 21, 23]. Xenografts and allografts may eliminate donor-site morbidity and decrease operating time; however, they result associated with the risk of severe immune response, transmission of infective diseases, and slower integration with the native tissue [24].

Several tissue engineering strategies have been explored using a variety of materials, ranging from synthetic to natural polymers, or their combination, to decellularized ECM, or cell-based approaches (Table 1) [3, 11, 18, 25]. All of these strategies have pros and cons, and even if many have shown promising outcomes in terms of SM regeneration, the proper cellular microenvironment to bioengineer the SM construct has not, till now, be found $[11,18,26]$.

\section{Decellularized ECM-Based Scaffolds for SM Regeneration}

Natural ECM is an heterogeneous microenvironment made of proteoglycans, proteins, and signaling molecules, providing architectural rigidity and mechanical support, regulating turgor pressure, forming intracellular connections, and modulating the binding sites and activity of growth factors (acting also as a local factor reservoir). The ECM composition influences matrix stiffness and rigidity (affecting cell differentiation, migration, and proliferation), permeability (affecting nutrient diffusion to tissues and cell function), and cellmatrix interactions (affecting cell adhesion and proliferation) [27]. As a consequence, the ECM acts as a structural and signaling microenvironment for cells, influencing cell behavior in terms of differentiation, proliferation, survival, and migration. Several studies demonstrated that, despite the improvements made till now, accurately mimicking the ECM complex structure is still lacking, and the reproduction of a scaffold capable to simulate complex tissues, such as SM, remains a technically unsolved issue $[25,28]$. 
TABLE 1: Current strategies for SM regeneration.

\begin{tabular}{|c|c|c|c|c|}
\hline Strategies & Materials & Engineered approaches & Pros & Cons \\
\hline $\begin{array}{l}\text { Natural } \\
\text { scaffold-based }\end{array}$ & $\begin{array}{l}\text { Alginate } \\
\text { Chitosan } \\
\text { Collagen } \\
\text { Fibrin } \\
\text { Hyaluronic acid } \\
\text { Laminin }\end{array}$ & $\begin{array}{l}\text { Fibrous meshes } \\
\text { Hydrogels } \\
\text { Porous scaffolds } \\
\text { Sponges }\end{array}$ & $\begin{array}{c}\text { Biocompatible } \\
\text { Intrinsic bioactive signaling cues } \\
\text { Facilitated controlled release of growth } \\
\text { factors } \\
\text { Can be configured in different forms } \\
\text { Can be chemically modified }\end{array}$ & $\begin{array}{l}\text { In vivo rapid degradation } \\
\text { Do not generate uniform cell } \\
\text { alignment and supported } \\
\text { disorganized repair of large } \\
\text { muscle defects } \\
\text { Limited mechanical stiffness }\end{array}$ \\
\hline $\begin{array}{l}\text { Synthetic } \\
\text { scaffold-based }\end{array}$ & $\begin{array}{c}\text { Poly (glycolic acid) } \\
\text { Poly (lactic acid) } \\
\text { Poly-e-caprolactone } \\
\text { Poly(lactic-co- } \\
\text { glycolic acid) } \\
\text { Polydimethylsiloxane } \\
\text { Polyurethane } \\
\text { Copolymers (e.g., } \\
\text { PLLA/PLGA) }\end{array}$ & $\begin{array}{c}\text { Fibers } \\
\text { Fibrous meshes } \\
\text { Micro-/nanopattered } \\
\text { substrates } \\
\text { Microspheres } \\
\text { Porous sponge-like } \\
\text { scaffolds }\end{array}$ & $\begin{array}{l}\text { Possess precisely tuned mechanical and } \\
\text { structural properties } \\
\text { Flexible in chemical and physical } \\
\text { modification } \\
\text { Reproducibility in preparation, } \\
\text { modification, and chemical properties } \\
\text { Readily fabricated into a variety of } \\
\text { geometries } \\
\text { Availability of various processing } \\
\text { technologies allowing the fabrication of } \\
\text { tissue shape and size-specific scaffolds } \\
\text { with control on mechanical, structural, } \\
\text { and physicochemical properties }\end{array}$ & $\begin{array}{l}\text { Low bioactivity } \\
\text { Need functionalization to } \\
\text { improve cell attachment or } \\
\text { regenerative outcomes } \\
\text { Possible foreign body } \\
\text { response }\end{array}$ \\
\hline $\begin{array}{l}\text { Decellularized } \\
\text { scaffolds }\end{array}$ & $\begin{array}{l}\text { Small intestine } \\
\text { submucosa } \\
\text { Urinary bladder } \\
\text { Muscle-derived }\end{array}$ & $\begin{array}{l}\text { As it is } \\
\text { Hydrogels } \\
\text { Minced tissue } \\
\text { (for muscle) }\end{array}$ & $\begin{array}{c}\text { Retain ECM architecture and complexity, } \\
\text { including vasculature and biofactors } \\
\text { Angiogenic, promotes vascularization } \\
\text { Significantly improve functional } \\
\text { outcomes }\end{array}$ & $\begin{array}{c}\text { Decellularization process can } \\
\text { significantly damage ECM } \\
\text { structure and protein/growth } \\
\text { factor content } \\
\text { Incomplete decellularization } \\
\text { can induce an inflammatory } \\
\text { response }\end{array}$ \\
\hline Cell-based & $\begin{array}{l}\text { Mesenchymal stem } \\
\text { cells } \\
\text { Mesoangioblasts } \\
\text { Myoblasts } \\
\text { Pericytes } \\
\text { Satellite cells }\end{array}$ & $\begin{array}{l}\text { Systemic injections } \\
\text { Seeded/loaded/injected } \\
\text { on scaffolds/hydrogels } \\
\text { Encapsulated in } \\
\text { microspheres }\end{array}$ & $\begin{array}{l}\text { Promote muscle regenerative capability } \\
\text { Can form new muscle fibers }\end{array}$ & $\begin{array}{c}\text { Low cell viability } \\
\text { Poor cell migration and } \\
\text { engraftment } \\
\text { Need of immunosuppressive } \\
\text { therapy } \\
\text { Inefficient methods of delivery } \\
\text { High costs for cell expansion } \\
\text { and manipulation }\end{array}$ \\
\hline $\begin{array}{l}\text { Molecular } \\
\text { signaling } \\
\text { based }\end{array}$ & $\begin{array}{c}\text { FGF } \\
\text { HGF } \\
\text { IGF-1 } \\
\text { PEDF } \\
\text { SDF-1a } \\
\text { TGF- } \beta 1 \\
\text { VEGF } \\
\text { Antisense specific } \\
\text { nucleotides } \\
\text { (e.g., nusinersen) }\end{array}$ & $\begin{array}{l}\text { Systemic injections } \\
\text { Incorporated in } \\
\text { scaffolds/hydrogels }\end{array}$ & $\begin{array}{c}\text { Activate and/or recruit host stem cells } \\
\text { Enhance myogenesis } \\
\text { Promote angiogenesis } \\
\text { Functional recovery with } \\
\text { revascularization }\end{array}$ & $\begin{array}{l}\text { Short factor half-life } \\
\text { Difficulty in controlled release }\end{array}$ \\
\hline
\end{tabular}

ECM-based materials provide an effective means for capturing this complexity and can assist as inductive templates for constructive remodeling [28]. Decellularization has been widely used for the development of ECM-based scaffolds, which retain the architecture and complexity of the native tissues, including vasculature and ECM biofactors [27, 29]. Moreover, it has been suggested that dECM-based bioscaffolds generate low molecular weight matricryptic oligopeptides with the ability to recruit and influence endogenous progenitor cells, playing a role in the constructive and functional remodeling process, including vasculature and inner- vation formation [30, 31]. Current models of VML have demonstrated the ability of ECM to stimulate a degree of neomyogenesis, confirming the critical proof of concept to use dECM for muscle regeneration [32].

Different tissue sources, both nontissue-specific and skeletal muscle, have been used so far to produce acellular scaffolds for the treatment of muscle loss.

3.1. Nontissue-Specific dECM. Small intestine submucosa matrix (SIS) and urinary bladder matrix (UBM) have been commonly considered, both for animal and clinical studies, 
as nontissue-specific ECM scaffolds for the treatment of muscle loss $[26,27,33]$. These scaffolds provided constructive tissue remodeling, including the formation of site-appropriate SM tissue, and promoted perivascular stem cell mobilization and accumulation within the site of injury [31, 34, 35]. Despite these positive results, reduced fiber generation, significant fibrotic tissue formation, and insufficient functional recovery have also been reported $[36,37]$.

SIS and UBM scaffolds are produced from thin tissues and not only do not have any muscular specific components, such as laminin $\alpha 1$ and $\alpha 2[38,39]$, but they do not possess specific properties found in SM such as alignment and muscle-specific biochemistry as well [40]. Being ECM spatial arrangement, composition, and interaction with cells and growth factor tissue- and functional-specific, it is plausible to suggest that nontissue-specific ECM scaffolds can be unlikely suitable matrices for an appropriate muscular regeneration.

3.2. Skeletal Muscle dECM. 3D architecture has a significant relevance for the regeneration of complex organs and tissues: in particular, the alignment of SM cells, allowing the formation of organized myotubes, is an essential topographic cue in musculoskeletal myogenesis [41, 42]. SM dECM retains its native morphology, supporting muscle healing and promoting a proregenerative immune response, implant integration, and tissue regeneration [43], and preserves the correct ECM architecture surrounding each myofiber [30]. On the basis of these considerations, SM ECM could play a critical role in acute regeneration, (i) orchestrating myoblast chemotaxis, proliferation, and fusion to form myotubes; (ii) releasing specific ECM growth factors and biomolecules that trigger satellite cell activation; and (iii) thus promoting myofiber differentiation, alignment and, ultimately, regeneration of functional SM [44].

To date, different animal models have been used as tissue source to develop SM dECM. Each animal model has its pros and cons, and no one completely matches the needed properties to be organ donors for humans (Figure 1).

Most of the studies have focused their attention on porcine muscles, due to their anatomical and physiological similarities to humans. However, the risk of porcine endogenous retroviruses, which may integrate to the host genome, is inevitable [49]. Human-derived SM dECMs have been obtained with positive results [50,51], even if the shortage of cadaveric donor organs significantly delays the obtainment of biological substitutes and increase patients' waiting time [52].

Different attempts to isolate and process SM dECM have been evaluated, and the main decellularization protocols, applied in the last years, are essentially of two types: detergent and detergent-enzymatic treatments (Table 2). Although most of these processes efficiently remove cellular components, at the same time, they can have negative effects on the composition, ultrastructure, biological activity, and biomechanical property of the remaining ECM, affecting the subsequent host response $[73,74]$. Moreover, the effectiveness of the decellularization process depends also on animal source, muscle type, and dimensions.
To obtain a bioengineered muscular tissue construct, the resulting SM dECM has been used in a number of different ways: (i) as scaffold, maintaining the shape of the original tissue or organ; (ii) as hydrogel-type ECM; and (iii) as electrospun ECM-based structures.

Aulino et al. demonstrated that dECM scaffolds, guiding migration and differentiation of stem cells, could represent a suitable environment not only for myogenesis but also for cartilage and bone formation [75]. Orthotopic transplanted diaphragm-derived ECM supported a local immune response, activating a proregenerative environment and stimulating host muscle progenitor cell activation and migration [58]; moreover, the same decellularized scaffold was able to promote generation of new blood vessels, new muscle fibers, and most importantly, to partially recover host diaphragmatic function in a mouse model of congenital diaphragmatic hernia [61]. Promising results have been also collected dealing with abdominal dECM scaffolds aimed to treat partial thickness and full abdominal wall defects in a rat model $[60,70]$. Furthermore, decellularized rat muscle matrix, characterized by an aligned structure, enhanced muscle function and regeneration in a large volumetric muscle defect, supporting the formation of new neuromuscular junctions and vascular networks $[55,56]$. Decellularized human SM samples have been tested to close a surgical defect of the abdominal rectus muscle: muscle graft induced neovascularization together with initial proliferation of muscle fibers and migration of progenitor cells [76]. Even though neat SM dECMs have shown promise in VML models, there remain obstacles in modulating physicochemical properties and scaling such materials to clinically relevant shapes and sizes. Many scientists have sought to overcome these limitations by enzymatically digesting these materials and, taking advantage of their natural thermoresponsive properties, fabricate scaffolds to be used as injectable hydrogel for promoting SM regeneration [53, 67]. For instance, SM dECM hydrogel combined with hyaluronic acid was used as a substrate for muscle progenitor cells and proved to be an optimal culture microenvironment potentially due to its similarity to the in vivo environment, suggesting a possible use for cellbased therapy for SM dysfunction [77]. Ungerleider et al. demonstrated that SM ECM-based hydrogels supported functional outcomes through altering key pathways associated with inflammatory response, cell death and survival, metabolism, and vessel and muscle development [68]. A nanofibrous SM ECM hydrogel allowed an improved myoblast viability, engraftment, and ischemic limb perfusion in vivo [54]. Although successful outcomes have been obtained to control size, shape, and structural integrity/stability of dECM hydrogel-based constructs (such as crosslinking modifications), the digestion required for their formation often inactivates important ECM components, and there is a limited control over the internal architecture of the material [78]. Electrospinning, allowing the fabrication of micro- and nanofibers tuning the diameter, alignment, and scaffold porosity $[79,80]$, has been used to collect an aligned structure that resulted similar to the anisotropic arrangement of stretched SM myofibers and provided a topographic cue for morphogenesis [25]. Smoak et al. developed a 

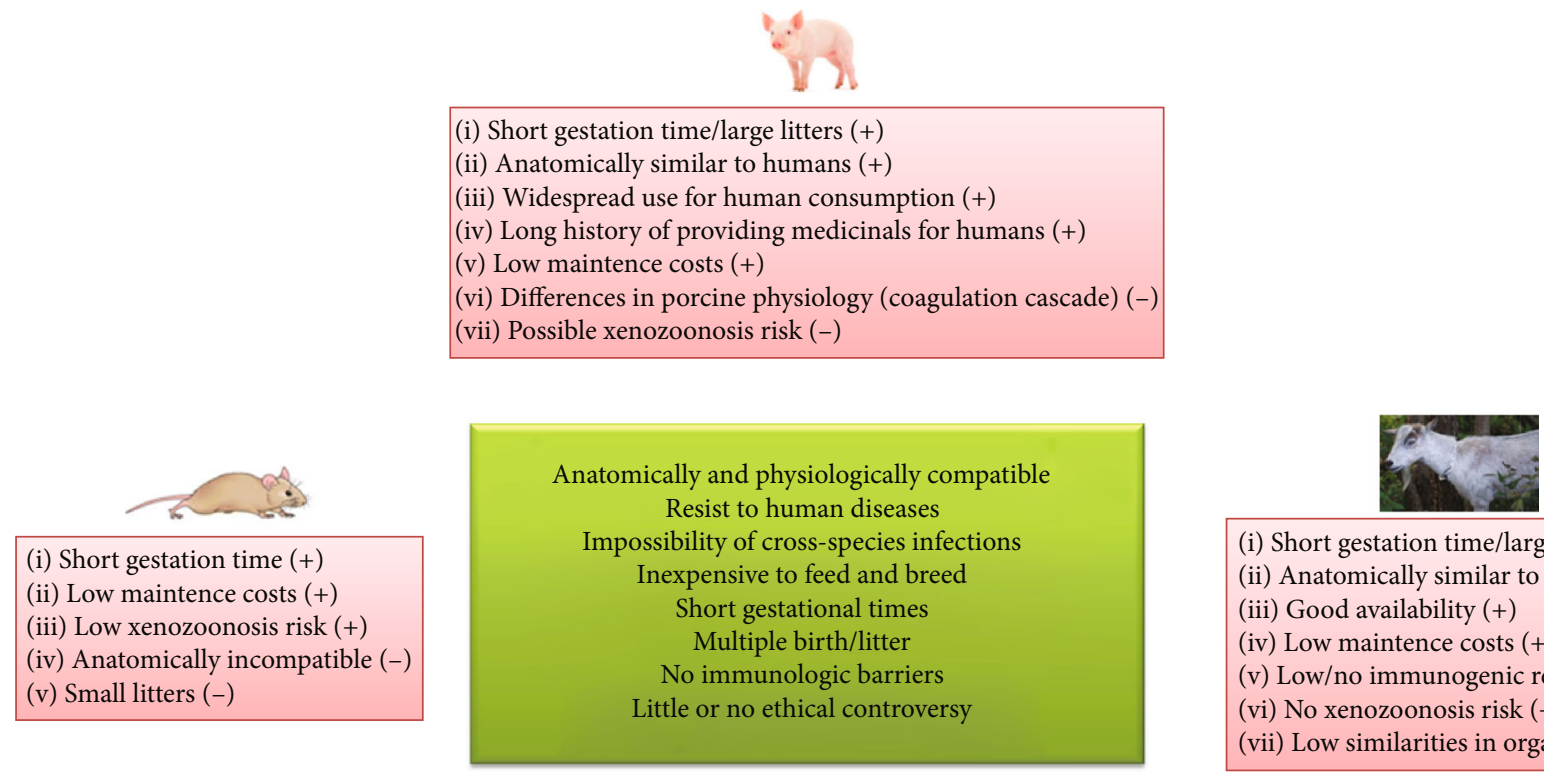

(i) Short gestation time/large litters $(+)$

(ii) Anatomically similar to humans (+)

(iii) Good availability $(+)$

(iv) Low maintence costs (+)

(v) Low/no immunogenic reaction $(+)$

(vi) No xenozoonosis risk (+)

(vii) Low similarities in organ sizes $(-)$

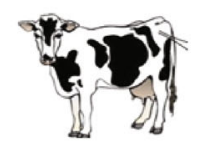

(i) Anatomically similar to humans (+)

(ii) Widespread use for human consumption (+)

(iii) Low maintence costs (+)

(iv) Long gestation time/slow breeding (-)

(v) Low similarities in organ sizes (-)

(vi) Possible xenozoonosis risk (-)

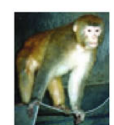

(i) Anatomically and physiologically similar to humans (+)

(ii) Possess resistence to human diseases (+)

(iii) Long gestation/small litters/slow breeding (-)

(iv) High maintence costs (-)

(v) High xenozoonosis risk (-)

FIgURE 1: Animal properties to be organ donors for humans (central box) and pros (+) and cons (-) of different animal sources [45-48].

novel, high-throughput procedure to fabricate electrospun dECM scaffolds with tunable physicochemical characteristics, while maintaining the structural matrix components required for SM regeneration [63]. An electrospun scaffold, composed of SM dECM aligned nanofibers and polycaprolactone (PCL), supported satellite cell growth, myogenic protein expression, and myokine production [57]. The same scaffold, implanted in a VML murine model, modulated macrophage-mediated inflammation and increased myofiber regeneration. However, improvements in muscle weights and force production were not observed [81]. Recently, a multiscale composite scaffold, made of aligned electrospun dECM nanofibers, led to suitably align muscle cells alongside a nanosized ECM basal lamina [65]. While successfully, electrospun dECM-based scaffolds, due to relatively thin structures and low mechanical stability, cannot recapitulate the physiological microenvironment to bioengineer a threedimensional volumetric SM tissue construct. To overcome this limitation, recent developments in 3D printing technologies can support the fabrication of volumetric tissue-like structures with a complex geometry in a layer-by-layer fashion.

\section{Additive Manufacturing for SM Regeneration}

3D printing technologies may allow to produce patientspecific implants with structural complexity, capable to mimic tissue morphological and biochemical cues [82]. The main advantage of this fabrication approach is related to the control that can be exerted on the processing variables from the design stage to the final product. These features can contribute to realize the expected microarchitecture by stacking several layers, generally reproducing a regular pattern. A regular 3D printed pattern is often considered a suitable option to control the expected functionality and cell distribution [83], but a tissue engineered scaffold should be regarded as a temporary substitute of the natural ECM of the tissue to be healed, resembling the complex tissue hierarchy, and this implies an effective biomimetic approach [8486]. Following this rationale, a few studies are aimed at introducing a random microarchitecture to mimic tissue-specific ECM, e.g., bone tissue [87, 88], by means of 3D printing.

The potential of this approach can be usefully implemented for SM tissue engineering [89-91]. Topographical cues have been considered one of the main requirements to guide myoblast/stem cell response and induce myogenic differentiation and maturation, and anisotropic environment promotes cell alignment, their fusion, and myogenesis [92]. To complete the rational design of a tissue engineered construct, not only the biological characteristics have to be considered but also the scaffold processing conditions that obviously concur to the desired positive outcome. In this regard, among all the available AM technologies, stereolithography may offer a valid alternative to fabricate ad hoc 
TABLE 2: Decellularization protocols for skeletal muscle dECM obtainment reported in the last 5 years.

\begin{tabular}{|c|c|c|c|c|}
\hline Method & Materials & Muscle & Results & Ref \\
\hline \multirow{6}{*}{ Detergent } & \multirow{6}{*}{$\begin{array}{l}\text { Sodium dodecyl } \\
\text { sulfate } \\
\text { Triton X-100 } \\
\text { Sodium } \\
\text { deoxycholate }\end{array}$} & Porcine skeletal & $\begin{array}{l}\text { Suitable decellularization using only SDS } \\
\text { Production of a too thin gel for hydrogel }\end{array}$ & {$[53]$} \\
\hline & & Porcine major psoas & Suitable decellularization & [54] \\
\hline & & Rat gastrocnemius & Unaltered ECM anisotropy and chemical components & {$[55]$} \\
\hline & & Rat hind limb & $\begin{array}{l}\text { Suitable decellularization } \\
\text { Loss of specific sarcolemma proteins }\end{array}$ & {$[56]$} \\
\hline & & Bovine tail & Suitable decellularization & {$[57]$} \\
\hline & & $\begin{array}{l}\text { Human flexor } \\
\text { digitorum } \\
\text { superficialis }\end{array}$ & ECM decellularized with unaltered composition & {$[51]$} \\
\hline \multirow{11}{*}{ Detergent/enzymatic } & \multirow{11}{*}{$\begin{array}{c}\text { Det }+ \\
\text { deoxyribonuclease } \\
\text { Det }+ \\
\text { ribonuclease A } \\
\text { Det + Trypsin }\end{array}$} & $\begin{array}{l}\text { Rat, rabbit, human } \\
\text { skeletal }\end{array}$ & $\begin{array}{l}\text { Triton+trypsin resulted more effective in removing } \\
\text { cellular material and maintaining the } 3 \mathrm{D} \text { fiber networks }\end{array}$ & {$[50]$} \\
\hline & & Rat diaphragm & $\begin{array}{c}\text { Suitable decellularization } \\
\text { ECM conservation, tissue micro- and ultra-architecture } \\
\text { preservation }\end{array}$ & {$[58]$} \\
\hline & & Porcine skeletal & $\begin{array}{c}\text { Suitable decellularization and gelation using } \\
\text { trypsin/EDTA, Triton X-100, and Triton X-100/SDS }\end{array}$ & {$[53]$} \\
\hline & & $\begin{array}{l}\text { Human rectus } \\
\text { femoris and } \\
\text { supraspinatus }\end{array}$ & Suitable decellularization & [59] \\
\hline & & $\begin{array}{l}\text { Porcine rectus } \\
\text { abdominal }\end{array}$ & $\begin{array}{l}\text { ECM decellularized } \\
\text { Altered ECM proteins levels }\end{array}$ & {$[60]$} \\
\hline & & Rat diaphragm & Suitable decellularization & $\begin{array}{l}{[61} \\
62]\end{array}$ \\
\hline & & Rabbit hind leg & $\begin{array}{l}\text { ECM decellularized with unaltered collagen, proteins, and } \\
\text { sGAG levels } \\
\text { Loss of stiffness }\end{array}$ & {$[63]$} \\
\hline & & Rabbit lower limb & $\begin{array}{l}\text { Suitable decellularization } \\
\text { Altered collagen levels } \\
\text { Increased pore sizes }\end{array}$ & {$[64]$} \\
\hline & & Porcine skeletal & $\begin{array}{l}\text { Suitable decellularization } \\
\text { Altered collagen, GAGs, and elastin levels } \\
\text { No proper structural stability }\end{array}$ & {$[65]$} \\
\hline & & Porcine lower limb & $\begin{array}{l}\text { ECM decellularized with altered collagen, elastin, and } \\
\text { sGAG levels }\end{array}$ & {$[66]$} \\
\hline & & $\begin{array}{l}\text { Human flexor } \\
\text { digitorum } \\
\text { superficialis }\end{array}$ & ECM not completely decellularized & {$[51]$} \\
\hline \multirow[b]{2}{*}{ Detergent/alcohol } & \multirow[b]{2}{*}{$\begin{array}{l}\text { Det }+ \text { isopropanol } \\
\text { Det }+ \text { methanol }\end{array}$} & Porcine psoas & Suitable decellularization & $\begin{array}{l}{[67,} \\
68]\end{array}$ \\
\hline & & $\begin{array}{l}\text { Porcine longissimus } \\
\text { dorsi }\end{array}$ & $\begin{array}{c}\text { Suitable decellularization } \\
\text { Difference in fat and protein compositions depending on } \\
\text { harvesting conditions }\end{array}$ & [69] \\
\hline \multirow{2}{*}{ Detergent/enzymatic/Alcohol } & & $\begin{array}{l}\text { Porcine rectus } \\
\text { abdominis }\end{array}$ & $\begin{array}{c}\text { ECM decellularized } \\
\text { Altered ECM proteins levels }\end{array}$ & {$[70]$} \\
\hline & & $\begin{array}{l}\text { Porcine tibialis } \\
\text { anterior }\end{array}$ & Suitable decellularization & $\begin{array}{l}{[71} \\
72]\end{array}$ \\
\hline \multirow[b]{2}{*}{ No detergent/no enzymatic } & \multirow{2}{*}{$\begin{array}{l}\text { Latrunculin B } \\
\text { Potassium } \\
\text { chloride } \\
\text { Potassium iodide }\end{array}$} & Rat hind limb & $\begin{array}{l}\text { Suitable decellularization } \\
\text { Loss of VEGF }\end{array}$ & {$[56]$} \\
\hline & & $\begin{array}{l}\text { Human flexor } \\
\text { digitorum } \\
\text { superficialis }\end{array}$ & ECM not completely decellularized & [51] \\
\hline
\end{tabular}


scaffolds characterized by a higher level of morphological details, possibly enhancing the SM tissue engineering expectations. This fabrication option can finely mimic specific structural features of the tissue to be healed, thus providing a more biomimetic environment.

Combining specific AM approaches and viable biological components can pave the way to the development of bioactive scaffolds. Such a strategy can support the preparation of actual tissue engineered constructs, being already threedimensionally biologically conditioned with respect to those undergoing to a postprocessing stage in terms of functionalization and cell seeding, which may not affect the whole structure.

\subsection{Bioprinting $d E C M$ Scaffolds. The main technologies used} for 3D deposition and patterning of biological materials in the bioprinting sector are inkjet, microextrusion, and laser assisted printing; each of them being characterized by different features related to surface resolution, cell viability, and biological materials to be processed. Inkjet printers allow to release controlled volumes of liquid at predefined locations by means of a number of delivering modes, such as thermal or piezoelectric, and can provide high cell viability, i.e., $\geq 85 \%[14,91]$. Microextrusion printers deliver a controlled volume of a material as a continuous strand by means of pneumatic or mechanical (piston or screw) systems, the most common mechanisms. Due to shear stresses, cell viability is generally lower (range survival rate 40-86\%) [14]. Laserassisted bioprinting relies on a ribbon made from glass which is coated with a laser-energy-absorbing layer (e.g., gold or titanium) and loaded with the bioink. A laser pulse focused on the metal film produces a high-pressure bubble that propels cell-containing materials toward the substrate; cell viability is usually high ( $\geq 95 \%)$ [91]. However, a suitable result is strictly related to fast gelation kinetics and compatibility of working wavelengths to preserve the resolution and arrangement of cells and biomaterials in 3D printed scaffolds [93].

In this framework, irrespective from the bioprinting technique, the bioink is the main actor of the experimental setup, whose characteristics, commonly those of a hydrogel, should be finely tuned and preserved. In addition, it should have the same composition and function of the native ECM which varies from tissue to tissue, and most of hydrogels for bioprinting unlikely provide this complexity [74]. The possibility to tailor the formulation of the bioink in order to promote a biomimetic response, combining not only cells, but also the tissue-specific ECM to modulate the critical cellular processes is a strategic key-point for a properly manufactured engineered scaffold.

Currently, natural and synthetic polymers are employed as bioinks for bioprinting SM constructs [91, 94]. Naturally derived hydrogels, such as collagen, alginate, and gelatin, have been used to provide physical support and cell instructive functionalities; others, such as calcium alginate or fibrin, characterized by fast crosslinking properties, have been used directly as bioink or as a supporting polymers [91]. Natural hydrogels can promote cell growth, are tunable, and characterized by biodegradable properties; however, they lack the specific mechanical features necessary for a suitable muscle regeneration. Due to their good mechanical strength, synthetic polymers, such as PEG-based hydrogels, poly(lacticco-glycolic acid), PCL, PVA, and polyurethane have been frequently considered for bioprinting SM constructs [91, 94]. The conjugation with functional groups resulted necessary to make synthetic polymers photocrosslinkable; while to enrich the scaffold with cell supportive properties, composite bioinks of natural-synthetic polymers have been used [91].

Most of the prepared hydrogels for bioprinting does not show the structural, chemical, biological, and mechanical complexity of natural ECM microenvironment for cells engraftment, survival, and function. Therefore, dECM, due to its unique tissue-specific composition and topology, and containing peculiar proteins, important signals for cell fate, could be the optimal material for preparing biomimetic bioinks [47, 73, 74].

Several studies investigated the topic, showing the potential of this approach to design novel and active biomaterials, assessing dECM from different tissues, e.g., porcine cartilage and heart tissues and human adipose tissue [95], kidney [96], bovine Achilles tendon [97], or porcine heart mechanically tailored by using vitamin B2 and UVA irradiation followed by thermal crosslinking to resemble native cardiac tissue and promote cardiac differentiation of progenitor cells [98]. Focusing on SM tissue engineering, Choi et al. prepared a bioink including porcine SM dECM and C2C12 myoblasts to be processed by means of in-house developed 3D cellprinting system [71]. PCL was deposited at both ends of the construct as a geometrical constraint to induce cell alignment, which was also dependent on the printed linewidth of the scaffold. Authors showed that the highest alignment was obtained for diameters of $500 \mu \mathrm{m}$, and as previously reported, the possible implication of the shear force, generated at the nozzle during the printing process, was assessed by cell viability tests which resulted in a minimal cell death after $24 \mathrm{~h}$. In addition, mechanical properties were improved as well when compared to the control group [71]. This study substantially reported the suitability of the SM dECM with no particular mention to possible drawbacks. Porcine SM dECM was further investigated as an active means for bioink preparation, considering a methacrylation process to obtain a photocrosslinkable bioink, to be processed by means of a three-axis printing system equipped with a $30 \mathrm{G}$ single nozzle [66]. The printable material also included fibrillated PVA, as a sacrificial polymer to fabricate a uniaxially oriented patterned structure, and $\mathrm{C} 2 \mathrm{C} 12$ myoblasts that were responsive to this culturing strategy. PVA concentrations affected the cell response, since high cell viability $(>94 \%)$ was assessed for a polymer content of 5 and $10 \mathrm{wt} \%$, while a low cell viability $(27.2 \pm 4.1 \%)$ resulted for a PVA concentration of $15 \mathrm{wt} \%$, due to the high viscosity of the bioink. A more comprehensive approach assessed the potential of AECM from porcine tibialis anterior muscle and descending aorta, including human SM cells and human umbilical vein endothelial cells, respectively, to be printed in a mixed solution or coaxially [72]. The constructs were fabricated via an in-house developed 3D cell printing system, named the integrated composite tissue/organ building system, at $18^{\circ} \mathrm{C}$ to prevent $\mathrm{dECM}$ bioink gelation. The experimental plan intended to treat VML issues (about 40\%) in a rat model and showed that 
prevascularized muscle constructs, coaxially fabricated, successfully mimicked the hierarchical architecture of vascularized muscles. Improved de novo muscle fiber formation, vascularization, innervations, and $85 \%$ functional recovery in VML injuries were collected with respect to constructs consisting of only muscle cells and SM dECM bioink and constructs made by mixing human umbilical vein endothelial cells, muscle cells, SM dECM, and vascular dECM bioink, both used for comparison.

4.2. Stereolithography of $d E C M$ Scaffolds. Stereolithography is an AM technique which relies on the layer photopolymerization of specific material by means of light irradiation, usually $\mathrm{UV}$, according to a CAD input. Commonly to all 3D printing methodologies, the final structure is the result of stacked layers as the build stage is vertically translated. This working principle can be implemented in two different modes: in the first one, the movement of the light source is computer controlled to precisely polymerize each layer of the structure, while in the other one, called digital micromirror device, an array of thousand micromirrors can polymerize a whole layer at once by controlling each of them to reflect light in a spatial pattern [90]. Stereolithography is characterized by the highest resolution of all the bioprinting methods $(\sim 6 \mu \mathrm{m})$, which can be further improved by the two-photon polymerizationbased stereolithography $(\sim 200 \mathrm{~nm})$. Polymerization is achieved by focusing two consecutive photons within the focal volume of a laser beam, and therefore, the polymerization threshold is not reached out of the focal volume. Typically, this technical approach allows to deal with treated volume less than $1 \mu \mathrm{m}^{3}$ [99]. Two-photon polymerization promoted the fabrication of scaffolds with nanoscale features similar to those of natural ECM, and this enables the possibility to further evaluate the cell response to this kind of environment [100].

Respect to other 3D printing technologies, stereolithography has several advantages as the scaffold external geometry and internal architecture can be finely controlled due to the intrinsic high resolution, being related to the spot size of the light source, and complex scaffolds can be thus easily fabricated [82], also allowing to modify printed scaffolds to add further functionalities [101, 102]. However, stereolithography is affected by some drawbacks as well. Only photopolymerizable solutions containing UV-activated photo-initiators can be processed, and the potential cytoxicity is a crucial issue to be addressed with polymeric suspension including cells, still representing a possible limitation also for acellular scaffolds due to the possible presence of unreacted compounds. Moreover, cells are exposed to UV radiation, and this may impair their functionality and affect viability.

In terms of scaffold manufacturing, currently no $3 \mathrm{D}$ printing technology can be considered as the optimal option to realize a functional tissue or organ. Stereolithography has the highest resolution but lacks scalability and detailed investigations on photo-initiated cell damage, and the long-term effects of laser/UV radiation on cells represent a real need. Droplet-based systems can precisely pattern cells, but bioprinting human scale tissue is still an onerous task. Extrusion-based bioprinting has the least resolution of all the $3 \mathrm{D}$ printing technologies but has the highest potential to bioprint human scale tissues and organs [90].

To obtain biomimetic stereolithographic scaffolds, cellladen photopolymerizable solutions, including not only cells but also specific biochemical compounds, like tissue-specific ECM, have been currently tested. In this regard, Chen et al. fabricated a pig cartilage dECM/gelatin methacrylate/exosome scaffold with radially oriented channels using desktop-stereolithography technology [103]. Scaffolds were then implanted into osteochondral defects in New Zealand white rabbits, finding that they contributed to restore cartilage mitochondrial dysfunction, enhance chondrocyte migration, and polarize the synovial macrophage response. Elomaa et al. proposed to replace gelatin methacrylate with methacryloyl-functionalized rat liver $\mathrm{AECM}$, due to its difficult viscosity control [104]. However, this formulation was not assessed as the study focused on printability and subsequent characterization of 3D printed acellular human small intestine-mimicking tissue scaffolds made of gelatin methacrylate/poly ( $\varepsilon$-caprolactone) methacrylate, and only a printed test case was shown. Biomimetic microarchitectures were proposed by $\mathrm{Yu}$ et al. to pattern cell-laden 3D dECM heart and liver tissue constructs for promoting the maturation of human-induced pluripotent stem cell- (hiPSC-) derived cardiomyocytes and hiPSC-hepatocytes [105]. The issue to deal with a photocrosslinkable dECM was addressed, showing that the fabricated scaffolds guided spontaneous cellular reorganization into predesigned striated heart and lobular liver structures through biophysical cues.

Further studies exploiting the potential of stereolithography should be carried out in order to prepare bioactive scaffolds accurately mimicking SM ECM properties as, to date and to Authors' best knowledge, no investigations included this biological structure in the preparation of the photocrosslinkable solution. The higher resolution allowed in the processing stage can effectively support the development of experimental protocols properly tailored to deal with instructive means for this specific tissue regeneration.

\section{Future Perspective}

The interest toward AM for tissue engineering applications can actually contribute to open novel routes to address critical regenerative issues and provide alternative approaches to respond to urgent clinical needs. In this framework, biomimetics can play a pivotal role to support an effectively healing process, and the design of novel scaffolds should be thus accurately tailored. VML treatment can be planned defining ad hoc protocols based on the selection of tissue-specific biomaterials and $3 \mathrm{D}$ printing techniques capable to process bioactive tissue-derived materials. The analysis here presented may support an experimental study in which the dECM from SM tissue can be the suitable biomaterial for stereolithography manufacturing, aimed to reproduce the fine morphological characteristics of muscle fibers. Physiological datasets, for instance, may be the starting point to elaborate a CAD model reproducing the tissue configuration and representing an ad hoc input for 3D printing (Figure 2). 


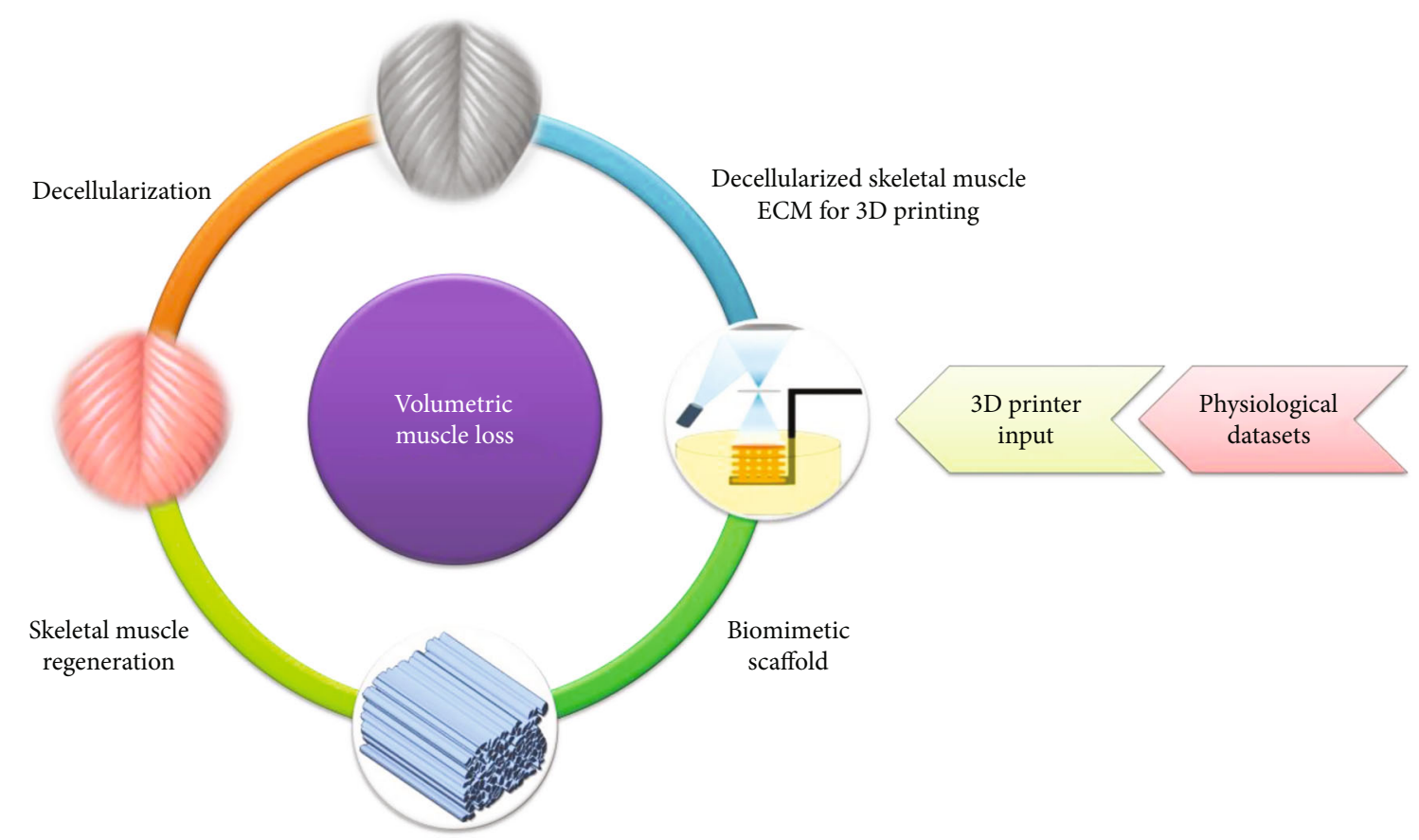

FIgURE 2: Schematic proposal of a 3D biomimetic scaffold for SM regeneration. Physiological datasets, e.g., histological images of SM fibers, may be the starting point to elaborate a CAD model reproducing the tissue configuration and then provide an ad hoc input to be processed by 3D printing, e.g., stereolithography, using SM dECM.

Tissue-specific dECM can provide the structural properties to match those of the natural tissue and all the necessary biochemical cues to design engineered scaffolds. For this aim, stereolithography seems to be one of the most promising manufacturing technique, thanks to its inherent properties even if an in-depth analysis is still necessary to verify the expected reliability.

\section{Conclusions}

AM can be a valuable option to design and fabricate biomimetic scaffolds with the aim to improve the expected outcome for tissue engineering applications. As here shown, focusing on SM regeneration, the tissue-specific dECM can be properly elaborated to be $3 \mathrm{D}$ printed as a structural and bioactive material for scaffold preparation. Cells, ECM, and biological compounds can be encapsulated into a supportive hydrogel to formulate a tailored bioink which allows to control the microstructure and three-dimensionally locate instructive inputs, being both two fundamental key-players of the tissue engineering paradigm.

The here presented paper reports the state-of-the-art for the SM regeneration, showing at the same time possible issues to be addressed and critically discuss the potential of AM for clinical needs. Bioprinting and stereolithography can provide significant evidences to develop promising therapeutic strategies, thanks to a more direct implementation of the first technique and to an intrinsic process resolution of the latter one that may contribute to effectively mimic the tissue-specific ECM.

\section{Conflicts of Interest}

The authors declare that there is no conflict of interests regarding the publication of this paper.

\section{Authors' Contributions}

Silvia Baiguera and Costantino Del Gaudio contributed equally to the work. Felicia Carotenuto and Laura Teodori contributed equally to the work as senior authors.

\section{Acknowledgments}

SB fellowship is supported by the research project "SMARTIES" (Smart scaffold ingegnerizzati per la rigenerazione dell'apparato muscolo scheletrico) founded by Regione Lazio. We want to express the greatest thanks to Dr. Martina Di Cesare (Lazio-Innova) for the excellent management of the SMARTIES funds. We also would like largely to thank Andrea Reale and Flavia Miele (ENEA CR Frascati) for their precious technical assistance to the SMARTIES progetto and Anna Pagliardini (ENEA CR Frascati) for her administrative support. This work was supported by the Regione Lazio through LazioInnova, Progetto "SMARTIES" (Smart scaffold ingegnerizzati per la rigenerazione dell'apparato muscolo scheletrico), coordinated by ENEACR Frascati (Grant Number: 85-2017-15004), Avviso Pubblico Progetti Di Gruppi Di Ricerca Conoscenza e cooperazione per un nuovo modello di sviluppo (LR 13/2008-art. 4). Support has been also provided by "Tor Vergata" University (Grant "Mission: Sustainability" (DR 2817/2016), Number: E86C18000640005). The authors 
acknowledge support from the Progetto: Biomechanical Scaling Stimula: Inducing Differentiation (BIOMESSID), coordinated by Dept. of Clinical Science and Translational Medicine, University of Rome "Tor Vergata," Italy.

\section{References}

[1] V. J. Mase, J. R. Hsu, S. E. Wolf et al., "Clinical application of an acellular biologic scaffold for surgical repair of a large, traumatic quadriceps femoris muscle defect," Orthopedics, vol. 33, no. 7, p. 511, 2010.

[2] B. F. Grogan and J. R. Hsu, "Volumetric muscle loss," The Journal of the American Academy of Orthopaedic Surgeons, vol. 19, pp. S35-S37, 2011.

[3] J. Liu, D. Saul, K. O. Böker, J. Ernst, W. Lehman, and A. F. Schilling, "Current methods for skeletal muscle tissue repair and regeneration," BioMed Research International, vol. 2018, Article ID 1984879, 11 pages, 2018.

[4] B. J. Kwee and D. J. Mooney, "Biomaterials for skeletal muscle tissue engineering," Current Opinion in Biotechnology, vol. 47, pp. 16-22, 2017.

[5] C. G. Y. Ngan, A. Quigley, R. M. I. Kapsa, and P. F. M. Choong, "Engineering skeletal muscle - from two to three dimensions," Journal of Tissue Engineering and Regenerative Medicine, vol. 12, no. 1, pp. e1-e6, 2018.

[6] R. J. Petrie, A. D. Doyle, and K. M. Yamada, "Random versus directionally persistent cell migration," Nature Reviews Molecular Cell Biology, vol. 10, no. 8, pp. 538-549, 2009.

[7] H. N. Kim, D. H. Kang, M. S. Kim, A. Jiao, D. H. Kim, and K. Y. Suh, "Patterning methods for polymers in cell and tissue engineering," Annals of Biomedical Engineering, vol. 40, no. 6 , pp. 1339-1355, 2012.

[8] X. Wang, B. Ding, and B. Li, "Biomimetic electrospun nanofibrous structures for tissue engineering," Materials Today, vol. 16, no. 6, pp. 229-241, 2013.

[9] J. R. Sanes, "The basement membrane/basal lamina of skeletal muscle," Journal of Biological Chemistry, vol. 278, no. 15, pp. 12601-12604, 2003.

[10] S. Hayashi, H. Aso, K. Watanabe et al., "Sequence of IGFI, IGF-II, and HGF expression in regenerating skeletal muscle," Histochemistry and Cell Biology, vol. 122, pp. 427-434, 2000.

[11] J. M. Grasman, M. J. Zayas, R. L. Page, and G. D. Pins, "Biomimetic scaffolds for regeneration of volumetric muscle loss in skeletal muscle injuries," Acta Biomaterialia, vol. 25, pp. 2-15, 2015.

[12] B. M. Sicari, J. P. Rubin, C. L. Dearth et al., "An acellular biologic scaffold promotes skeletal muscle formation in mice and humans with volumetric muscle loss," Science Translational Medicine, vol. 6, no. 234, article 234ra58, 2014.

[13] L. Armstrong, M. Lako, N. Buckley et al., "Editorial: Our top 10 developments in stem cell biology over the last 30 years," Stem Cells, vol. 30, no. 1, pp. 2-9, 2012.

[14] S. V. Murphy and A. Atala, "3D bioprinting of tissues and organs," Nature Biotechnology, vol. 32, no. 8, pp. 773-785, 2014.

[15] S. Stranding, "Functional anatomy of the muscoskeletal system," in Gray's Anatomy-The Anatomical Basis of Clinical Practice, Elsevier, Amsterdam, The Netherlands, 41st edition, 2016.
[16] S. Schiaffino and C. Reggiani, "Fiber types in mammalian skeletal muscles," Physiological Reviews, vol. 91, no. 4, pp. 1447-1531, 2011.

[17] S. Grefte, A. M. Kuijpers-Jagtman, R. Torensma, and J. W. Von den Hoff, "Skeletal muscle development and regeneration," Stem Cells and Development, vol. 16, no. 5, pp. 857$868,2007$.

[18] G. D. Mulbauer and H. W. T. Matthew, "Biomimetic scaffolds in skeletal muscle regeneration," Discoveries, vol. 7, no. 1, article e90, 2019.

[19] P. Kannus, J. Parkkari, T. L. N. Järvinen, T. A. H. Järvinen, and M. Järvinen, "Basic science and clinical studies coincide: active treatment approach is needed after a sports injury," Scandinavian Journal of Medicine \& Science in Sports, vol. 13, no. 3, pp. 150-154, 2003.

[20] T. A. Jarvinen, T. L. Jarvinen, M. Kaariainen, H. Kalimo, and M. Jarvinen, "Muscle injuries: biology and treatment," The American Journal of Sports Medicine, vol. 33, pp. 745-764, 2017.

[21] P. De Coppi, S. Bellini, M. T. Conconi et al., "Myoblast-acellular skeletal muscle matrix constructs guarantee a long-term repair of experimental full-thickness abdominal wall defects," Tissue Engineering, vol. 12, no. 7, pp. 1929-1936, 2006.

[22] B. Bianchi, C. Copelli, S. Ferrari, A. Ferri, and E. Sesenna, "Free flaps: outcomes and complications in head and neck reconstructions," Journal of Cranio-Maxillo-Facial Surgery, vol. 37, no. 8, pp. 438-442, 2009.

[23] N. J. Turner and S. F. Badylak, "Regeneration of skeletal muscle," Cell and Tissue Research, vol. 347, pp. 759-774, 2012.

[24] A. R. Gazdag, J. M. Lane, D. Glaser, and R. A. Forster, "Alternatives to autogenous bone graft: efficacy and indications," Journal of the American Academy of Orthopaedic Surgeons, vol. 3, no. 1, pp. 1-8, 1995.

[25] T. H. Qazi, D. J. Mooney, M. Pumberger, S. Geissler, and G. N. Duda, "Biomaterials based strategies for skeletal muscle tissue engineering: existing technologies and future trends," Biomaterials, vol. 53, pp. 502-521, 2015.

[26] A. Urciuolo and P. De Coppi, "Decellularized tissue for muscle regeneration," International Journal of Molecular Sciences, vol. 19, no. 8, article 2392, 2018.

[27] S. Baiguera, L. Urbani, and C. Del Gaudio, "Tissue engineered scaffolds for an effective healing and regeneration: reviewing orthotopic studies," BioMed Research International, vol. 2014, Article ID 398069, 27 pages, 2014.

[28] B. N. Brown and S. F. Badylak, "Extracellular matrix as an inductive scaffold for functional tissue reconstruction," Translational Research, vol. 163, no. 4, pp. 268-285, 2014.

[29] S. F. Badylak, D. J. Weiss, A. Caplan, and P. Macchiarini, "RETRACTED: engineered whole organs and complex tissues," The Lancet, vol. 379, no. 9819, pp. 943-952, 2012.

[30] L. Teodori, A. Costa, R. Marzio et al., "Native extracellular matrix: a new scaffolding platform for repair of damaged muscle," Frontiers in Physiology, vol. 5, p. 218, 2014.

[31] J. Dziki, S. Badylak, M. Yabroudi et al., "An acellular biologic scaffold treatment for volumetric muscle loss: results of a 13patient cohort study," npj Regenerative Medicine, vol. 1, no. 1, article 16008, 2016.

[32] T. L. Sarrafian, S. C. Bodine, B. Murphy, J. K. Grayson, and S. M. Stover, "Extracellular matrix scaffolds for treatment of large volume muscle injuries: a review," Veterinary Surgery, vol. 47 , no. 4, pp. 524-535, 2018. 
[33] B. T. Corona and S. M. Greising, "Challenges to acellular biological scaffold mediated skeletal muscle tissue regeneration," Biomaterials, vol. 104, pp. 238-246, 2016.

[34] N. Han, M. A. Yabroudi, K. Stearns-Reider et al., "Electrodiagnostic evaluation of individuals implanted with extracellular matrix for the treatment of volumetric muscle injury: case series," Physical Therapy, vol. 96, no. 4, pp. 540-549, 2016.

[35] J. Ma, S. Sahoo, A. R. Baker, and K. A. Derwin, "Investigating muscle regeneration with a dermis/small intestinal submucosa scaffold in a rat full-thickness abdominal wall defect model," Journal of Biomedical Materials Research Part B, Applied Biomaterials, vol. 103, no. 2, pp. 355364, 2015.

[36] A. Aurora, J. L. Roe, B. T. Corona, and T. J. Walters, “An acellular biologic scaffold does not regenerate appreciable de novo muscle tissue in rat models of volumetric muscle loss injury," Biomaterials, vol. 67, pp. 393-407, 2015.

[37] S. M. Greising, J. C. Rivera, S. M. Goldman, A. Watts, C. A. Aguilar, and B. T. Corona, "Unwavering pathobiology of volumetric muscle loss injury," Scientific Reports, vol. 7, no. 1, article 13179, 2017.

[38] Z. X. Mahoney, T. S. Stappenbeck, and J. H. Miner, "Laminin alpha 5 influences the architecture of the mouse small intestine mucosa," Journal of Cell Science, vol. 121, no. 15, pp. 2493-2502, 2008.

[39] S. Liu, H. Yamashita, B. Weidow, A. M. Weaver, and V. Quaranta, "Laminin-332- $\beta 1$ integrin interactions negatively regulate invadopodia," Journal of Cellular Physiology, vol. 223, no. 1, pp. 134-142, 2009.

[40] K. Ahmad, S. Shaikh, S. S. Ahmad, E. J. Lee, and I. Choi, "Cross-talk between extracellular matrix and skeletal muscle: implications for myopathies," Frontiers in Pharmacology, vol. 11, p. 142, 2020.

[41] T. Boontheekul, E. E. Hill, H. J. Kong, and D. J. Mooney, "Regulating myoblast phenotype through controlled gel stiffness and degradation," Tissue Engineering, vol. 13, no. 7, pp. 1431-1442, 2007.

[42] D. Klumpp, R. E. Horch, U. Kneser, and J. P. Beier, "Engineering skeletal muscle tissue-new perspectives in vitro and in vivo," Journal of Cellular and Molecular Medicine, vol. 14, no. 11, pp. 2622-2629, 2010.

[43] B. Perniconi, D. Coletti, P. Aulino et al., "Muscle acellular scaffold as a biomaterial: effects on $\mathrm{C} 2 \mathrm{C} 12$ cell differentiation and interaction with the murine host environment," Frontiers in Physiology, vol. 5, p. 354, 2014.

[44] S. F. Badylak, J. L. Dziki, B. M. Sicari, F. Ambrosio, and M. L. Boninger, "Mechanisms by which acellular biologic scaffolds promote functional skeletal muscle restoration," Biomaterials, vol. 103, pp. 128-136, 2016.

[45] M. F. Levy, "Animal organs for human transplantation: how close are we?," Baylor University Medical Center Proceedings, vol. 13, no. 1, pp. 3-6, 2017.

[46] D. K. Cooper and R. Bottino, "Recent advances in understanding xenotransplantation: implications for the clinic," Expert Review of Clinical Immunology, vol. 11, no. 12, pp. 1379-1390, 2015.

[47] D. Choudhury, H. W. Tun, T. Wang, and M. W. Naing, "Organ-derived decellularized extracellular matrix: a game changer for bioink manufacturing?," Trends in Biotechnology, vol. 36, no. 8, pp. 787-805, 2018.
[48] T. Agarwal, T. K. Maiti, and S. K. Ghosh, "Decellularized caprine liver-derived biomimetic and pro-angiogenic scaffolds for liver tissue engineering," Materials Science \& Engineering C, Materials for Biological Applications, vol. 98, pp. 939-948, 2019.

[49] M. C. Kimsa, B. Strzalka-Mrozik, M. W. Kimsa et al., "Porcine endogenous retroviruses in xenotransplantation-molecular aspects," Viruses, vol. 6, no. 5, pp. 2062-2083, 2014.

[50] A. Porzionato, M. M. Sfriso, A. Pontini et al., "Decellularized human skeletal muscle as biologic scaffold for reconstructive surgery," International Journal of Molecular Sciences, vol. 16, no. 7, pp. 14808-14831, 2015.

[51] A. Naik, M. Griffin, M. Szarko, and P. E. Butler, "Optimizing the decellularization process of an upper limb skeletal muscle; implications for muscle tissue engineering," Artificial Organs, vol. 44, no. 2, pp. 178-183, 2019.

[52] S. Baiguera, C. Del Gaudio, M. O. Jaus et al., "Long-term changes to in vitro preserved bioengineered human trachea and their implications for decellularized tissues," Biomaterials, vol. 33, no. 14, pp. 3662-3672, 2012.

[53] Y. Fu, X. Fan, C. Tian et al., "Decellularization of porcine skeletal muscle extracellular matrix for the formulation of a matrix hydrogel: a preliminary study," Journal of Cellular and Molecular Medicine, vol. 20, no. 4, pp. 740-749, 2016.

[54] N. Rao, G. Agmon, M. T. Tierney et al., "Engineering an injectable muscle-specific microenvironment for improved cell delivery using a nanofibrous extracellular matrix hydrogel," ACS Nano, vol. 11, no. 4, pp. 3851-3859, 2017.

[55] M. J. McClure, D. J. Cohen, A. N. Ramey et al., "Decellularized muscle supports new muscle fibers and improves function following volumetric injury," Tissue Engineering Part A, vol. 24, no. 15-16, pp. 1228-1241, 2018.

[56] A. Urciuolo, L. Urbani, S. Perin et al., "Decellularised skeletal muscles allow functional muscle regeneration by promoting host cell migration," Scientific Reports, vol. 8, no. 1, article 8398, 2018.

[57] K. H. Patel, A. J. Dunn, M. Talovic et al., "Aligned nanofibers of decellularized muscle ECM support myogenic activity in primary satellite cells in vitro035010," Biomedical Materials, vol. 14, no. 3, 2019.

[58] M. Piccoli, L. Urbani, M. E. Alvarez-Fallas et al., "Improvement of diaphragmatic performance through orthotopic application of decellularized extracellular matrix patch," Biomaterials, vol. 74, pp. 245-255, 2016.

[59] K. Wilson, A. Terlouw, K. Roberts, and J. C. Wolchok, "The characterization of decellularized human skeletal muscle as a blueprint for mimetic scaffolds," Journal of Materials Science Materials in Medicine, vol. 27, no. 8, p. 125, 2016.

[60] Z. Yang, Z. Song, X. Nie et al., "Characteristic properties of muscular-derived extracellular matrix and its application in rat abdominal wall defects," Regenerative Medicine, vol. 13, no. 5, pp. 503-517, 2018.

[61] C. Trevisan, E. Maghin, A. Dedja et al., "Allogenic tissuespecific decellularized scaffolds promote long-term muscle innervation and functional recovery in a surgical diaphragmatic hernia model," Acta Biomaterialia, vol. 89, pp. 115125, 2019.

[62] C. Trevisan, M. E. A. Fallas, E. Maghin et al., "Generation of a functioning and self-renewing diaphragmatic muscle construct," Stem Cells Translational Medicine, vol. 8, no. 8, pp. 858-869, 2019. 
[63] M. M. Smoak, A. Han, E. Watson et al., "Fabrication and characterization of electrospun decellularized musclederived scaffolds," Tissue Engineering Part C, Methods, vol. 25, no. 5, pp. 276-287, 2019.

[64] L. Shapiro, E. Elsangeedy, H. Lee et al., "In vitro evaluation of functionalized decellularized muscle scaffold for in situ skeletal muscle regeneration," Biomedical Materials, vol. 14, no. 4 , article $045015,2019$.

[65] H. Lee, W. Kim, J. Lee, J. J. Yoo, G. H. Kim, and S. J. Lee, "Effect of hierarchical scaffold consisting of aligned dECM nanofibers and poly(lactide-co-glycolide) struts on the orientation and maturation of human muscle progenitor cells," ACS Applied Materials \& Interfaces, vol. 11, no. 43, pp. 39449-39458, 2019.

[66] W. Kim, H. Lee, J. Lee et al., "Efficient myotube formation in 3D bioprinted tissue construct by biochemical and topographical cues," Biomaterials, vol. 230, article 119632, 2020.

[67] J. L. Ungerleider, T. D. Johnson, N. Rao, and K. L. Christman, "Fabrication and characterization of injectable hydrogels derived from decellularized skeletal and cardiac muscle," Methods, vol. 84, pp. 53-59, 2015.

[68] J. L. Ungerleider, T. D. Johnson, M. J. Hernandez et al., "Extracellular matrix hydrogel promotes tissue remodeling, arteriogenesis, and perfusion in a rat hindlimb ischemia model," JACC: Basic to Translational Science, vol. 1, no. 1-2, pp. 32-44, 2016.

[69] M. J. Hernandez, G. E. Yakutis, E. I. Zelus et al., "Manufacturing considerations for producing and assessing decellularized extracellular matrix hydrogels," Methods, vol. 171, pp. 20-27, 2020.

[70] J. Zhang, Z. Q. Hu, N. J. Turner et al., "Perfusion-decellularized skeletal muscle as a three-dimensional scaffold with a vascular network template," Biomaterials, vol. 89, pp. 114126, 2016.

[71] Y. J. Choi, T. G. Kim, J. Jeong et al., “3D cell printing of functional skeletal muscle constructs using skeletal musclederived bioink," Advanced Healthcare Materials, vol. 5, no. 20, pp. 2636-2645, 2016.

[72] Y. J. Choi, Y. J. Jun, D. Y. Kim et al., “A 3D cell printed muscle construct with tissue-derived bioink for the treatment of volumetric muscle loss," Biomaterials, vol. 206, pp. 160-169, 2019.

[73] K. Dzobo, K. S. C. M. Motaung, and A. Adesida, "Recent trends in decellularized extracellular matrix bioinks for 3D printing: an updated review," International Journal of Molecular Sciences, vol. 20, no. 18, p. 4628, 2019.

[74] F. Kabirian and M. Mozafari, "Decellularized ECM-derived bioinks: prospects for the future," Methods, vol. 171, pp. 108-118, 2020.

[75] P. Aulino, A. Costa, E. Chiaravalloti et al., "Muscle extracellular matrix scaffold is a multipotent environment," International Journal of Medical Sciences, vol. 12, no. 4, pp. 336340, 2015.

[76] A. Porzionato, E. Stocco, S. Barbon, F. Grandi, V. Macchi, and R. De Caro, "Tissue-engineered grafts from human decellularized extracellular matrices: a systematic review and future perspectives," International Journal of Molecular Sciences, vol. 19, no. 12, p. 4117, 2018.

[77] D. Zhang, Y. Zhang, Y. Zhang et al., "Tissue-specific extracellular matrix enhances skeletal muscle precursor cell expansion and differentiation for potential application in cell therapy," Tissue Engineering. Part A, vol. 23, no. 15-16, pp. 784-794, 2017.

[78] B. B. Rothrauff, G. Yang, and R. S. Tuan, "Tissue-specific bioactivity of soluble tendon-derived and cartilage-derived extracellular matrices on adult mesenchymal stem cells," Stem Cell Research \& Therapy, vol. 8, no. 1, p. 133, 2017.

[79] C. Del Gaudio, A. Bianco, M. Folin, S. Baiguera, and M. Grigioni, "Structural characterization and cell response evaluation of electrospun PCL membranes: micrometric versus submicrometric fibers," Journal of Biomedical Materials Research Part A, vol. 89A, no. 4, pp. 1028-1039, 2009.

[80] E. Ercolani, C. Del Gaudio, and A. Bianco, "Vascular tissue engineering of small-diameter blood vessels: reviewing the electrospinning approach," Journal of Tissue Engineering and Regenerative Medicine, vol. 9, no. 8, pp. 861-888, 2015.

[81] K. H. Patel, M. Talovic, A. J. Dunn et al., "Aligned nanofibers of decellularized muscle extracellular matrix for volumetric muscle loss," Journal of Biomedical Materials Research Part B, Applied Biomaterials, vol. 108, no. 6, pp. 2528-2537, 2020.

[82] D. G. Tamay, T. Dursun Usal, A. S. Alagoz, D. Yucel, N. Hasirci, and V. Hasirci, "3D and 4D printing of polymers for tissue engineering applications," Frontiers in Bioengineering and Biotechnology, vol. 7, p. 164, 2019.

[83] S. Wüst, R. Müller, and S. Hofmann, "Controlled positioning of cells in biomaterials-approaches towards 3D tissue printing," Journal of Functional Biomaterials, vol. 2, no. 3, pp. 119-154, 2011.

[84] R. C. Dutta and A. K. Dutta, "Cell-interactive 3D-scaffold; advances and applications," Biotechnology Advances, vol. 27, no. 4, pp. 334-339, 2009.

[85] Y. Kim, H. Ko, I. K. Kwon, and K. Shin, "Extracellular matrix revisited: roles in tissue engineering," International Neurourology Journal, vol. 20, pp. S23-S29, 2016.

[86] A. Gilpin and Y. Yang, "Decellularization strategies for regenerative medicine: from processing techniques to applications," BioMed Research International, vol. 2017, Article ID 9831534, 13 pages, 2017.

[87] R. Pecci, S. Baiguera, P. Ioppolo, R. Bedini, and C. Del Gaudio, "3D printed scaffolds with random microarchitecture for bone tissue engineering applications: manufacturing and characterization," Journal of the Mechanical Behavior of Biomedical Materials, vol. 103, article 103583, 2020.

[88] S. Gómez, M. D. Vlad, J. López, and E. Fernández, "Design and properties of $3 \mathrm{D}$ scaffolds for bone tissue engineering," Acta Biomaterialia, vol. 42, pp. 341-350, 2016.

[89] I. Casanellas, A. García-Lizarribar, A. Lagunas, and J. Samitier, "Producing 3D biomimetic nanomaterials for musculoskeletal system regeneration," Frontiers in Bioengineering and Biotechnology, vol. 6, p. 128, 2018.

[90] S. Vijayavenkataraman, W. C. Yan, W. F. Lu, C. H. Wang, and J. Y. H. Fuh, "3D bioprinting of tissues and organs for regenerative medicine," Advanced Drug Delivery Reviews, vol. 132, pp. 296-332, 2018.

[91] S. Ostrovidov, S. Salehi, M. Costantini et al., "3D bioprinting in skeletal muscle tissue engineering," Small, vol. 15, no. 24, article e1805530, 2019.

[92] S. Jana, S. K. Levengood, and M. Zhang, "Anisotropic materials for skeletal-muscle-tissue engineering," Advanced Materials, vol. 28, no. 48, pp. 10588-10612, 2016. 
[93] I. Matai, G. Kaur, A. Seyedsalehi, A. McClinton, and C. T. Laurencin, "Progress in 3D bioprinting technology for tissue/organ regenerative engineering," Biomaterials, vol. 226, article 119536, 2020.

[94] A. Popov, S. Malferrari, and D. M. Kalaskar, "3D bioprinting for musculoskeletal applications," Journal of $3 D$ Printing in Medicine, vol. 1, no. 3, pp. 191-211, 2017.

[95] F. Pati, J. Jang, D. H. Ha et al., "Printing three-dimensional tissue analogues with decellularized extracellular matrix bioink," Nature Communications, vol. 5, no. 1, p. 3935, 2014.

[96] M. Ali, A. K. Pr, J. J. Yoo, F. Zahran, A. Atala, and S. J. Lee, “A photo-crosslinkable kidney ECM-derived bioink accelerates renal tissue formation," Advanced Healthcare Materials, vol. 8, no. 7, article e1800992, 2019.

[97] B. Toprakhisar, A. Nadernezhad, E. Bakirci, N. Khani, G. A. Skvortsov, and B. Koc, "Development of bioink from decellularized tendon extracellular matrix for 3D bioprinting," Macromolecular Bioscience, vol. 18, no. 10, article e1800024, 2018.

[98] J. Jang, T. G. Kim, B. S. Kim, S. W. Kim, S. M. Kwon, and D. W. Cho, "Tailoring mechanical properties of decellularized extracellular matrix bioink by vitamin B2-induced photo-crosslinking," Acta Biomaterialia, vol. 33, pp. 88-95, 2016.

[99] A. Spangenberg, N. Hobeika, F. Stehlin et al., "Recent advances in two-photon stereolithography," in Updates in Advanced Lithography, IntechOpen, 2013.

[100] S. A. Skoog, P. L. Goering, and R. J. Narayan, "Stereolithography in tissue engineering," Journal of Materials Science Materials in Medicine, vol. 25, no. 3, pp. 845-856, 2014.

[101] M. Ciocci, F. Mochi, F. Carotenuto et al., "Scaffold-in-scaffold potential to induce growth and differentiation of cardiac progenitor cells," Stem Cells and Development, vol. 26, no. 19, pp. 1438-1447, 2017.

[102] F. Carotenuto, L. Teodori, A. M. Maccari, L. Delbono, G. Orlando, and P. Di Nardo, "Turning regenerative technologies into treatment to repair myocardial injuries," Journal of Cellular and Molecular Medicine, vol. 24, no. 5, pp. 27042716, 2020.

[103] P. Chen, L. Zheng, Y. Wang et al., "Desktop-stereolithography $3 \mathrm{D}$ printing of a radially oriented extracellular matrix/mesenchymal stem cell exosome bioink for osteochondral defect regeneration," Theranostics, vol. 9, no. 9, pp. 24392459, 2019.

[104] L. Elomaa, E. Keshi, I. M. Sauer, and M. Weinhart, "Development of GelMA/PCL and dECM/PCL resins for 3D printing of acellular in vitro tissue scaffolds by stereolithography," Materials Science \& Engineering C, Materials for Biological Applications, vol. 112, article 110958, 2020.

[105] C. Yu, X. Ma, W. Zhu et al., "Scanningless and continuous 3D bioprinting of human tissues with decellularized extracellular matrix," Biomaterials, vol. 194, pp. 1-13, 2019. 